\title{
Cost of Biosecurity Application: Comparing Aquaculture System and Fish Health in Traditional Fish Farm
}

\author{
Nimmi Zulbainarni \\ School of Business \\ IPB University (Bogor Agricultural University) \\ Bogor, Indonesia \\ nimmizu@apps.ipb.ac.id
}

\author{
Lokita Rizky Megawati \\ School of Business \\ IPB University (Bogor Agricultural University) \\ Bogor, Indonesia \\ lokita.rizky@apps.ipb.ac.id
}

\begin{abstract}
The application of biosecurity in the aquaculture industry is seen as very important as one of the determinants of sustainable production. This application protects aquaculture from high mortality rates and low growth rates due to infection from pathogenic microorganisms and the introduction of exotic pathogenic that act as disease carriers. However, many traditional fish farmers have not implemented biosecurity due to limited capital. This paper objective is to assess the costs of biosecurity application in different aquaculture system in the traditional fish farm. This study collected data from previous literature and continued by cost simulation. Then we linked the results with the possible impact on health. The results prove that some practices in applying biosecurity in traditional fish farms have limited benefits due to an imbalance between the operating costs and substantial investments compare to fish productivity. Limited protection from biosecurity application caused a threat to fish and human health. This study concluded that biosecurity in traditional fish farms had limited ability to protect fish and human health.
\end{abstract}

Keywords - biosecurity, traditional fish farm, fish and human health, cost comparison

\section{INTRODUCTION}

The application of biosecurity in the aquaculture industry today is seen as very important as one of the determinants of sustainable production. This application is not only driven by the trend of global consumer demands to consume products originating from production systems that meet the safety and sustainable elements, but is also driven by high mortality rates and low growth rates due to infection with pathogenic microorganisms. Establishing biosecurity in aquaculture facilities is essential to prevent or limit the spread and spread of disease within or between fish production facilities. (M.A.R, Faruk, 2012)

The disease is one of the main obstacles to aquaculture and ultimately can be a limiting factor for the economic success of the emerging fish hatcheries. Most hatchery operators do not have a good understanding of health problems and diseases in their systems. Also, the health certification system or diagnostic laboratory in Indonesia to check the health status of broodstock and fish seeds is not comprehensive. As a result, fish farmers do not know whether their fish carry pathogens before stocking. Building biosecurity in aquaculture facilities is essential to prevent or limit the spread and spread of disease within or between fish production facilities. Designing an effective biosecurity program requires an understanding of aquaculture operations, general principles of disease transmission and knowledge of fish kept in facilities. The poultry industry has successfully implemented a biosecurity production system to prevent the spread of infectious diseases among farms. It can serve as a model for aquaculture as a reliable source of animal protein throughout the world (Lee and O'Bryen, 2002). Fish culture can use various biosecurity measures to prevent and control diseases in their fish.

The application of biosecurity in fish farms is inseparable from the aspect of cost components that must be added in the production process of fish farming. A thorough study of the simulation of operational costs and investment costs incurred for the application of biosecurity compared to fish productivity and linked with threats to fish and human health has not been performed before. Therefore, the purpose of this paper is to assess the costs of biosecurity applications in different aquaculture system on the traditional fish farm. This study collected data from previous literature and continued by cost simulation. Then we linked the results with the possible impact on health. The paper contributes specifically to biosecurity application literature that focuses on the aquaculture system and fish health impact.

\section{MATERIALS AND METHODS}

The study used a qualitative methodology by collected data from previous literature and continued by cost simulation with the possible impact on health. Cost comparisons will be made for two fish farming businesses, namely gold fish and milkfish. The calculated costs are operational costs and investment costs in making biosecurity on traditional fish farm, and risk costs to fish health and human health compared to productivity.

The study consist of three steps to carry out the analysis. First, the literature related to the application of biosecurity in traditional fish farms and the costs associated with making biosecurity in traditional fish farms in the form of operational costs, investment costs, and risk costs to productivity that have an impact on fish and human health. Literature study is conducted as a reference to the theory 
that is relevant to the case or problem found and also to understand in depth related to the object of research. Second, to find out how much it costs to apply biosecurity, a cost simulation is carried out by comparing the two aquaculture systems in a traditional fish farms. The third step calculates the assumption of the risk costs incurred to determine the productivity of the application of biosecurity.

\section{RESULTS}

The results prove that some practices in applying biosecurity in traditional fish farms have limited benefits due to an imbalance between the operating costs and substantial investments compare to fish productivity. Limited protection from biosecurity application caused a threat to fish and human health.

TABLE 1. COST COMPARISON IN TRADITIONAL FISH FARM

\begin{tabular}{|c|c|c|}
\hline COST COMPARISON & GOLDFISH FARM & MILKFISH FARM \\
\hline \multicolumn{3}{|l|}{ Operating Cost : } \\
\hline Salary expense & 4.800 .000 & 4.150 .000 \\
\hline Feed & 1.500 .000 & 22.327 .500 \\
\hline Medicine & 100.000 & 1.050 .400 \\
\hline Electricity cost & 800.000 & 1.800 .000 \\
\hline $\operatorname{Tax}(0,5 \%)$ & 112.500 & 300.000 \\
\hline Total Operating Cost & 7.312 .500 & 29.627 .900 \\
\hline \multicolumn{3}{|l|}{ Investment: } \\
\hline Larvae & 400.000 & 4.704 .000 \\
\hline Making fish ponds & 4.500 .000 & 5.000 .000 \\
\hline Water Pump + Water Storage Tank & 5.000 .000 & 8.500 .000 \\
\hline Aerator & 1.500 .000 & 2.500 .000 \\
\hline Electricity Installation Costs & 1.000 .000 & 1.000 .000 \\
\hline Oxygen tube & 500.000 & 500.000 \\
\hline Total Investment & 12.900 .000 & 22.204 .000 \\
\hline \multicolumn{3}{|l|}{ Risk Cost: } \\
\hline Fish Health (assume 10\%) & 2.021 .250 & 5.183 .190 \\
\hline Human Health (assume 5\%) & 1.010 .625 & 2.591 .595 \\
\hline Risk of failure & 1.000 .000 & 1.000 .000 \\
\hline Total Risk Cost & 4.031 .875 & 8.774 .785 \\
\hline Total Cost & 24.244 .375 & 60.606 .685 \\
\hline Productivity & 22.500 .000 & 60.000 .000 \\
\hline
\end{tabular}

The cost simulation above shows the occurrence of losses due to traditional fish ponds that are still limited in the biosecurity applications. The use of imperfect biosecurity applications does not profitable but rather a loss in terms of the risk of crop failure, fish health risk and the impact on human health risks that eat the fish by assuming loss by the risk of failure a fish health risk of $10 \%$ and a human health risk of $5 \%$. Biosecurity can be effective if it is based on an actual disease risk profile, efficient farm level strategies, good management practices in the form of testing, quarantine and vaccination. (International Biosecurity Conference, 2009)

\section{DISCUSSION}

Differences in recommended biosecurity practices for certain types of fish or production classes can encourage fish farmers to choose some of their favorite recommendations and allow them to create incomplete biosecurity programs that do not substantially reduce the risk of incoming disease. As such, we believe that aligning recommendations within each production class, especially when specific practices have been validated based on empirical evidence, will be beneficial. For example, quarantine time for new entrants must be based on published findings and any broad range must be explained. There are several questions about how far the biosecurity program in fish farms is necessary to prevent transmission of disease. Recommendations given to fish farmers must be based on the specific risks associated with the specific species being raised, the potential severity of disease threats, and the location and operation of traditional fish farms. In addition, the extent to which preventive measures are taken will vary depending on the level of threat, with more precautions taken during epidemics.

\section{CONCLUSION}

Biosecurity in traditional fish farms had limited ability to protect fish and human health. Biosecurity in traditional fish farms was to prevent the entry of disease into the culture system and its spread to other places. Biosecurity has not been done by many farmers because of: (a) lack of understanding and knowledge of biosecurity, (b) there is a lack of understanding between the aspects of costs incurred and the benefits from applying biosecurity. The success of biosecurity applications is influenced by technical, economic and managerial aspects.

\section{REFERENCES}

[1] A. Ayalew and Fufa Abunna. 2018. Maintenance of Fish Health in Aquaculture: Review of Epidemiological Approaches for Prevention and Control of Infectious Disease of Fish. ReviewArticle. Veterinary Medicine International Volume 2018.

[2] Biosecurity Cost 2019. http://www.cfsph.iastate.edu/BRMForProducers/English/Economics/ Biosecurity_costs_explained.pdf [Internet]

[3] B. Edgar. 2009. Economic Impact of Disease and biosecurity measures. International Biosecurity Conference.

[4] B.M.W. Gusti, and S. Komar. Business Feasibility Analysis of Gold Fish Cultivation Business in Limited Land in Jakarta. MPI Journal (2006).

[5] Faruk, M. A. R.. 2012. Status of Biosecurity and Health Management in Fish Hatcheries. IRJALS Research Paper, Bangladesh.

[6] F. Richard. 2016. Options to Strengthen On-farm Biosecurity Management for Commercial and Non-commercial Aquaculture. Technical Paper No: 2016/47

[7] G.D. Pruder. 2004. Biosecurity: application in aquaculture. Aquacultural Engineering 32 (2004) 3-10.

[8] Lee and P.J. O'Bryen. 2002. Biosecurity in Aquaculture Production Systems: Exclusion of Pathogens and Other Undesirables. The World Aquaculture Society, Baton Rouge, Louisiana, USA.

[9] P. Edmund. 2016. The Role of Risk Analysis and Epidemiology in the Development of Biosecurity for Aquaculture. https://www.researchgate.net/publication/267997123

[10] T. Riesti, and Himah. Feasibility Analysis of Shrimp and Milkfish Polyculture: A Case Study in Pasekan District, Indramayu Regency. Buletin Ilmiah "MARINA" Sosial Ekonomi Kelautan dan Perikanan Vol. 1 No. 1 (2015) 1-10.

[11] U. Mahfudlotul, and Nunung Kusnadi. 2016. Business Analysis of Milkfish Polyculture in Traditional and Semi-Intensive Technology in Karawang District. [Thesis]. 